\title{
Integrated case management of repeated intimate partner violence: a randomized, controlled trial
}

\author{
Jonathan Goosey ${ }^{1}$ - Lawrence Sherman ${ }^{2}$. \\ Peter Neyroud $^{3}$
}

Published online: 18 August 2017

(C) The Author(s) 2017. This article is an open access publication

\begin{abstract}
Research Question Can integrated case management by a multi-agency partnership of the relations between offenders and victims with repeated incidents of intimate partner violence (IPV) reduce the frequency or severity of harm from that violence?

Data Three batches of 60 IPV dyads were enrolled in a trial, with data collected on services delivered to them and police records for 2 years before and 2 years after random assignment to treatment and control groups.

Methods The study measured the delivery of all three elements of treatment offered: (1) victim support through Berkshire Women's Aid, (2) one-to-one perpetrator counselling through motivational interviewing techniques and (3) follow-up visits to the home addresses of perpetrators and victims. The outcomes for each couple in severity of harm were compared in a before-after, difference-of-differences analysis of Cambridge Crime Harm Index scores. After-only frequency of non-criminal domestic conflict events was also compared.

Findings Delivery of programme elements was highly variable, but more intense in the treatment group than in control, especially in terms of police visits to offenders ( $\mathrm{T}=60 \%, \mathrm{C}=$ zero). Mean difference between 24 months of post-random assignment and the 24 months baseline period for $\mathrm{C}$ cases was an increase of 4.15 Cambridge Crime Harm Index (CHI) prison days, while T cases had a mean change of 8.85 fewer $\mathrm{CHI}$ days in prison in post-assignment than in baseline. This difference was significant with outliers removed, but not with two control group baseline cases included. There was also a substantially higher rate of frequency of non-crime events in the 24 months after random assignment in $\mathrm{T}$ (112) than in $\mathrm{C}(85)$.
\end{abstract}

Lawrence Sherman

Lawrence.Sherman@crim.cam.ac.uk

1 Thames Valley Police, Kidlington, UK

2 Universities of Cambridge and Maryland, Cambridge, UK

3 University of Cambridge, Cambridge, UK 
Conclusions The overall effect of the programme appeared to have been beneficial, as measured by the Crime Harm Index. The evidence cannot specify how much of that benefit was caused by the more consistent police visits to offenders versus other elements of the programme for both victims and offenders.

Keywords Intimate partner violence - Policing - Integrated case management · Randomized trial $\cdot$ Multi-agency partnership

\section{Introduction}

Since the advent of randomized controlled trials in policing domestic violence (Sherman and Berk 1984), few studies have found reductions in repeat intimate partner violence (IPV) (Sherman et al. 1992). One reason may be that most IPV cases have no repetition reported to police (Bland and Ariel 2015; Barnham et al. 2017). Because the likelihood of further violence reported to police increases with the number of priors, it seems likely that a programme targeted on dyads with repeated reports to police might have a greater chance of showing a measurable effect. The greater statistical power of a higher base rate, if nothing else, may make a positive impact discernible and possibly even more cost-effective.

It is therefore an important advance in testing domestic abuse programmes to report this first randomized control trial (RCT) of police responses targeted on repeat-case IPV couples. This study reports the RCT, in which the police response was a randomly assigned engagement with a multi-agency partnership, providing an array of services to both victims and offenders. These services were designed to be selected on a customized basis for each couple, depending on their particular victim vulnerabilities or criminogenic needs. While that customisation creates a challenge for impact evaluation, it is also useful to reflect a prevailing view in operational practice that a customized response has a better chance of success than a one-size-fits-all approach.

This article reports on the effects of a programme in the county of Berkshire, England in the Thames Valley Police territory. The Domestic Abuse Service Coordination (DASC) Project commenced in April 2011 as a project funded by the Community Safety Partnership of Bracknell Forest Council to deal with cases of repeated domestic abuse. The plan of DASC was to provide an enhanced level of support to victims while also providing therapeutic interventions and supervision of perpetrators.

The initial cohort in 2011/2012 consisted of 11 couples. They were monitored by police to find a reduction from 69 repeat calls to the police in 2011/2012 compared to 24 calls in 2012/2013. While this apparent reduction in repeat offending could actually have been due to regression to the mean, additional funding was sourced from Thames Valley Police and the council to expand the DASC approach to a bigger cohort. This funding provided extra training in and capacity for the perpetrator service by increasing the number of available practitioners.

In 2013, as the expansion of DASC was about to begin, Chief Constable Sara Thornton convened a 1-day Thames Valley Police Evidence Based Policing conference, which featured presentations by Cambridge academics. The first author, who was Chair of the DASC Project, a police officer with the Force, approached the visitors from Cambridge with a proposal to test the DASC programme with a randomized 
controlled trial (RCT). The proposal was accepted and the first author enrolled in the Cambridge Police Executive Programme to conduct the trial as a master's thesis.

This article describes the multi-agency intervention model used in the trial, describing each of the partners involved in the DASC group, with their role and function in the project, as well as the data they collected on their collective work with each couple, both treatment and control. The research design identifies the steps before random assignment and the eligibility criteria applied to select the dyads to participate in the project. The findings report the treatment as implemented by the partner agencies and how they were delivered, as well as the before-after, difference-of-differences between experimental and control cases in post-randomisation prevalence, incidence and harm of incidents and crimes.

\section{The Multi-agency Integrated Case Management Programme}

The purpose of this study is to test the hypothesis that a multi-agency intervention approach to couples who repeatedly report domestic abuse (DA) to the police will reduce both the harms of subsequent incidents. The model used in this trial is the Domestic Abuse Service Coordination (DASC) project in the Bracknell Forest Local Police Area, a part of Thames Valley Police, in cooperation with Bracknell Forest Borough Council. The Borough sits to the west of London in Berkshire on the M4 Motorway and has a growing population of 113,200 (Office for National Statistics (ONS) 2013).

The DASC project was initiated in 2011 as a project funded by the Community Safety Partnership (CSP) to tackle domestic abuse. The CSP is composed of agencies including the police, the local authority, the fire authority and the health and probation services and is responsible for reducing crime and antisocial behaviour in the local community. The partners of the CSP agreed that the DASC should focus on reducing levels of severity of harm related to domestic abuse among intimate partners (dyads) who most frequently report domestic abuse incidents. Aside from the CSP, the partners involved in the DASC group came from a number of Bracknell Forest Council Services and external agencies as described in Table 1 as follows.

The project is structured by a monthly meeting of the partners, in which the agenda is to review the dyads who are receiving the service provision. For the purpose of the test by this randomized trial, it was the treatment group who formed the agenda of each meeting, not the control group. Agreements were then reached on which agency should supply which services, with what dosage, to the victim and offender in each dyad.

\section{Research Design}

Selection of Dyads and Eligibility The dyads used in the trial were identified through reports of domestic abuse incidents made to the police within the boundaries of Bracknell Forest Local Police Area. Reports included both crime and crime-related incidents (CRIs), which are reports of incidents where there is insufficient basis to record a crime.

The eligibility criteria applied to select the dyads to participate in the project were as follows: 
Table 1 Agencies involved in DASC

\begin{tabular}{|c|c|c|}
\hline Agency & Role & Function in DASC \\
\hline $\begin{array}{l}\text { Community Safety } \\
\text { Team }\end{array}$ & $\begin{array}{l}\text { Focus is on reducing crime and } \\
\text { antisocial behaviour, working } \\
\text { alongside other partners. }\end{array}$ & $\begin{array}{l}\text { Tactical coordination of DASC } \\
\text { project, including maintenance of } \\
\text { record keeping, actions completed } \\
\text { and distribution of minutes of } \\
\text { monthly meeting }\end{array}$ \\
\hline Police & $\begin{array}{l}\text { Maintain law and order, detect and } \\
\text { prevent crime and protect the } \\
\text { public }\end{array}$ & $\begin{array}{l}\text { Leadership and strategic coordination } \\
\text { of project. Provide information on } \\
\text { incidents reported by dyads and } \\
\text { updates on follow-up visits to } \\
\text { home addresses }\end{array}$ \\
\hline $\begin{array}{l}\text { Family Intervention } \\
\text { Project }\end{array}$ & $\begin{array}{l}\text { Part of the Youth Offending Service } \\
\text { and provide a dedicated worker to } \\
\text { support whole families through } \\
\text { any problems. }\end{array}$ & $\begin{array}{l}\text { Provide information sharing on the } \\
\text { dyads and their families who are } \\
\text { associated with the Family } \\
\text { Intervention Project, since family } \\
\text { poverty and other household } \\
\text { problems impact on domestic } \\
\text { abuse (Farmer and Callan 2012) }\end{array}$ \\
\hline $\begin{array}{l}\text { Drug and Alcohol } \\
\text { Service }\end{array}$ & $\begin{array}{l}\text { Support the recovery of people from } \\
\text { drug and alcohol misuse }\end{array}$ & $\begin{array}{l}\text { Provide information sharing on dyads } \\
\text { who are being treated for } \\
\text { substance misuse }\end{array}$ \\
\hline Children's Social Care & $\begin{array}{l}\text { Provide support and protect children } \\
\text { and young people. They will make } \\
\text { an assessment of what the needs } \\
\text { may be and provide appropriate } \\
\text { services }\end{array}$ & $\begin{array}{l}\text { Provide information sharing on those } \\
\text { dyads whose families are } \\
\text { supported by Children's Social } \\
\text { Care }\end{array}$ \\
\hline $\begin{array}{l}\text { Thames Valley } \\
\text { Probation }\end{array}$ & $\begin{array}{l}\text { The National Probation Service } \\
\text { supports the criminal justice } \\
\text { system, with responsibility for } \\
\text { supervising offenders in the } \\
\text { community and providing reports } \\
\text { to the criminal courts to assist them } \\
\text { with the sentencing of offenders. }\end{array}$ & $\begin{array}{l}\text { Provide information sharing on the } \\
\text { offending parties of the dyads who } \\
\text { are engaged with the Probation } \\
\text { Service }\end{array}$ \\
\hline $\begin{array}{l}\text { Youth Offending } \\
\text { Service (YOS) }\end{array}$ & $\begin{array}{l}\text { The service aims to prevent offending } \\
\text { by children and young people. The } \\
\text { YOS get involved if the young } \\
\text { person has been arrested, charged } \\
\text { and going to court or has been } \\
\text { convicted of an offence. }\end{array}$ & $\begin{array}{l}\text { Providing information sharing on any } \\
\text { children of dyads which may have } \\
\text { an impact on the behaviour of } \\
\text { those dyads }\end{array}$ \\
\hline $\begin{array}{l}\text { Domestic Abuse } \\
\text { Perpetrator Service } \\
\text { (DAPS) }\end{array}$ & $\begin{array}{l}\text { Provide a one-to-one perpetrator } \\
\text { counselling service }\end{array}$ & $\begin{array}{l}\text { To provide supporting information } \\
\text { from and represent Children's } \\
\text { Social Care } \\
\text { To provide updates from engagement } \\
\text { with offenders with DAPS }\end{array}$ \\
\hline $\begin{array}{l}\text { Enhanced Integrated } \\
\text { Offender } \\
\text { Management (IOM): } \\
\text { Plain Talking }\end{array}$ & $\begin{array}{l}\text { Provide a one-to-one perpetrator } \\
\text { counselling service }\end{array}$ & $\begin{array}{l}\text { To provide updates from follow-up } \\
\text { visits to dyads home addresses and } \\
\text { engagement with offenders on the } \\
\text { Plain Talking programme }\end{array}$ \\
\hline Bracknell Forest Homes & Manages the ex-council house stock & $\begin{array}{l}\text { Provides any information such as } \\
\text { complaints from neighbours and } \\
\text { any other issues relevant to dyads } \\
\text { living in their properties }\end{array}$ \\
\hline Berkshire Women's Aid & $\begin{array}{l}\text { Provide a support service, with } \\
\text { advice, counselling and places of } \\
\text { safety for victims of domestic } \\
\text { abuse }\end{array}$ & $\begin{array}{l}\text { Provide feedback on the contact } \\
\text { made and engagement with the } \\
\text { partners that are victims in the } \\
\text { dyads }\end{array}$ \\
\hline
\end{tabular}

Agencies directly treating offenders and victims highlighted are in italics 
- A male has perpetrated abuse against a female victim

- Spousal/intimate partners only

- Two or more reports made to the police about the dyad in the previous 12 months

- Not currently listed as a MARAC (serious domestic abuse) case

The criteria for two or more prior calls of domestic incidents to the police were put in place before the publication of evidence from Bland and Ariel (2015), who reported that only $25 \%$ of dyads of domestic abuse produced two or more reports over a period lasting up to 6 years. The assumption by the agencies in Bracknell Forest was that there is an increased level of offending and harm after two events. Bland and Ariel (2015) found no statistically significant elevation in $\mathrm{CHI}$ harm values associated with repeated incidents. They did, however, find an increased likelihood of the occurrence of further incidents after repeated incidents had occurred, so from the perspective of reducing repeat events, the DASC agencies were arguably correct in their selection criteria.

Dyads currently being dealt with by the Multi-Agency Risk Assessment Conference (MARAC) were excluded from eligibility. The MARACs support victims at the highest risk of high harm from domestic abuse (Robbins et al. 2014).

Random Assignment of Treatment and Control Status The experimental design for this test is a randomized control trial (RCT). The RCT was carried out in conjunction with the University of Cambridge to ensure independence of random assignment (Sherman 2010). The protocol for the randomized trial was documented in a Criminological Protocol for Operating Randomized Trials (CRIMPORT). The protocol contains the three original measures of experimental treatments to be offered, consisting of element $\mathrm{A}$, victim to be offered increased support; element $\mathrm{B}$, perpetrator to be offered one-to-one counselling sessions; and element $\mathrm{C}$, follow-up police visits to the home address of the victim and perpetrator if deemed appropriate by the DASC group.

Simultaneous or "batch" random assignment (Sherman 2010) was performed in three batches totalling 180 dyads split into three cohorts of 60 . The cohorts were staggered to ensure there was sufficient partner agency capacity to provide support to the DASC coordinating group and the treatments to be provided. Randomisation was used to limit the treatments to 30 dyads in each cohort of 60 and ensure that all eligible dyads were equally able to be assigned to either experimental cohort (Dunford 1990). The desire to stagger the other two cohorts was met by the delay in building up 60 further eligible cases through ongoing review of the "trickle-flow" of newly eligible cases (Sherman 2010). Once each eligible cohort was identified, it was randomly divided into two groups, consisting of 30 treatment dyads and 30 control dyads. The 180 eligible cases were achieved with cohort 1 commencing on the 1 April 2013, cohort 2 on the 1 August 2013 and cohort 3 on the 1 December 2013.

Randomisation was performed using a simple random numbers sequence programme by staff at the Institute of Criminology at the University of Cambridge to ensure that the randomisation could be objectively completed and not manipulated based on any local knowledge of the specific cases. This procedure mitigated against both programme practitioner and local researcher bias. The details of the treatment cohorts only were then provided to the DASC partnership group for the multi-agency intervention to commence. By ensuring that the providers were blind to the control 
cohorts, the integrity of the random assignment process was maintained (Sherman 2010).

Tracking Treatments Delivered to Experimental and Control Dyads The overall tracking and feedback was provided by partners at the monthly DASC meeting, where each case was discussed and actions updated. When no further treatment or actions were required in regard to a particular dyad, the case was moved and classed as monitoring before being closed. This enabled the information on each dyad to be maintained for further use and analysis at the end of the trial.

The responsibility of documenting this tracking of the implementation and delivery of the trial was given to the first author and the partners attending the monthly DASC meeting. The details of each case and the related actions and responses were updated at each meeting. Actions were expected to be completed within the same month between meetings. If the dyad, victim or offender could not be immediately contacted the action was carried forward it to the next meeting.

The treatment delivery was blinded in design to participants, but not to the treatment delivery staff. The eligible dyads were not aware they were going to receive the enhanced treatment until and unless they were contacted. All contacts with sample dyads were recorded, including control group members contacted in violation of the experimental protocol.

There was initial consideration of a proposal for the delivery of a letter to the victims in the treatment group dyads informing them that they were now part of an enhanced treatment programme. A few dyads in the first cohort did receive a letter, but this was abandoned soon after by decision of the partners in the DASC meeting. There were, in any case, implementation issues ensuring the letter was delivered to dyads at the beginning of any treatments. There was also a concern that a blanket delivery to all dyads in the treatment group may create an unacceptable escalation in risk, in the event that the letter was received by the offending party.

Treatment Delivery The delivery of treatment is presented below in Fig. 1 as a CONSORT Flow Diagram, in the format recommended by Schulz et al. (2010).

The treatments were carried out once they were agreed by the DASC meeting. The agencies had responsibility for ensuring delivery of a treatment, whether individually or collectively. For example, if a follow-up visit to an offender was to be carried out by the neighbourhood policing team and a treatment practitioner, they would arrange a mutually agreed appointment to attend the address at the same time.

\section{Data and Methods}

Data To support the organisation and retention of data, an Excel spreadsheet was maintained during and after the experiment. The partner data was retrieved on request of the individual agencies and the police data from police computer systems. The aim of using such an ongoing method of record keeping was to provide an easy transition into the analysis stage of the findings, so that there would not be any unnecessary delays in retrieving data at the conclusion of the experiment. 


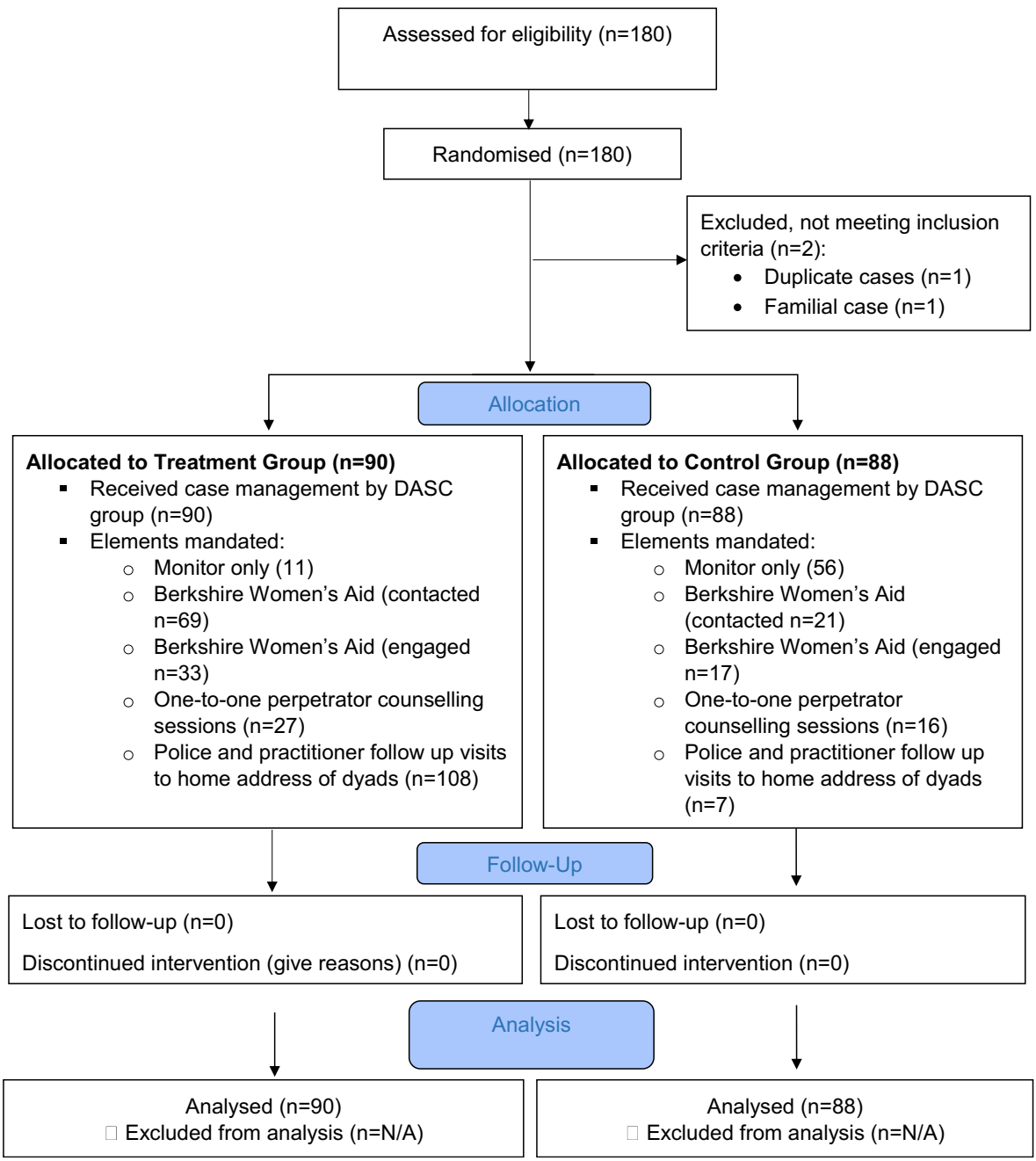

Fig. 1 CONSORT flow diagram - the consolidated standards of reporting trial statement provide a standard format for the reporting on RCTs

Data were collated on the five primary treatments in the programme:

1. The data, related to Berkshire Women's Aid (BWA), will include whether contact was made and the number of times the victim was engaged.

2. The number of referrals of the offender to the one-to-one counselling service with Bracknell Domestic Abuse Perpetrator Service (DAPS)

3. The number of sessions completed under the referral of the perpetrator to the Enhanced Integrated Offender Manager (IOM) for the Plain Talking programme

4. The number of follow-up welfare checks to the dyad home addresses by the Police Neighbourhood Team

5. How many practitioner visits were made to the home addresses, either alone or jointly with the Police Neighbourhood Team, for support and welfare checks. 
In addition, primary police data were extracted on the number of domestic offences (crime and non-crime) for 2 years prior to treatment period for both control and treatment cohorts, during the treatment period of 6 months and for 18 months beyond the treatment period (and its equivalent for the control cases).

Analysis Plan Our analysis compares offending post-random assignment between the treatment and control groups 2 years after the initial randomisation process was completed by the treatment cohorts. The actual count of and type of offences committed is provided, as is the number and types of treatments received by both treatment and (in violation) control groups.

Cambridge Crime Harm Index A comparison of the measure of the increase or decrease in harm from 2 years before and 2 years after random assignment is made between the treatment and control groups by measuring the seriousness of the offences with the Cambridge Crime Harm Index (CHI) (Sherman et al. 2016). The CHI translates each crime type into a value related to the starting point sentence recommended for a first-time offender by the Sentencing Guidelines Council.

\section{Findings}

\section{Treatment as Implemented}

The treatments that were available to be delivered to the parties in the dyads are stated as follow in Table 2. The indication of $N$ is a prevalence measure showing one or more instance of each treatment being delivered within each dyad.

There were three elements of treatments offered in the experiment, consisting of increased support to victims, one-to-one counselling sessions for perpetrators and follow-up police and practitioner visits to the home address of the victim and perpetrator. These were also supplied to some of those in the control group. This occurred due to the multi-agency processes that work in parallel to the DASC such as child protection and the fact that the partner agencies involved in the DASC group were blinded to the identity of the control group dyads.

Even so, a far larger percentage of the treatment group, $87.78 \%$ compared to $36.36 \%$ of the control group, received any of the experimental treatments as can be seen from Fig. 2 .

A further breakdown for the treatment group illustrates that 11 of the 90 were only monitored. This was down to the decision-making process of the partnership DASC group. On deciding what treatments and support each dyad should be offered, in those 11 cases, it was decided that no further support should be offered. The follow-up visits by the neighbourhood police officers and/or one-to-one counsellor enhanced integrated offender manager were the most numerous treatments delivered. This was followed closely behind by the support offered to the victims by Berkshire Women's Aid.

The number of referrals by the DASC partnership group to the treatment group totalled 242. The control group prompted 68 referrals. These were made because of the contractual obligations and services offered by the agencies, not because of decision making by the DASC group itself. The mean number per case equates to 2.69 for the treatment group and 0.77 for the control group. 
Table 2 Treatments as delivered by DASC

Service

1. Victim referral to BWA — contacted Referral to Berkshire Women's Aid (BWA) to provide support to the victim. BWA made contact with the victim, primarily by telephone or if no contact was made and it was deemed appropriate, via letter or a personal visit to the home address.

$N$ in treatment group $=69 / 90=77 \%$

$N$ in control group $=21 / 88=24 \%$

2. Victim referral to BWA - engaged The victim was provided with information and support of the choices available to them to address their varying needs. The Independent Domestic Violence Advisor (IDVA) employed by BWA offered a variety of support provided within the role of an IDVA including the following:

Arranging refuge accommodation; on-going safety planning and risk management advice, depending on client's circumstances; active participation in Child Protection framework; assistance with injunctions for clients; advocacy - regular contact and close cooperation with other multi-agency partners; signposting; on-going emotional support to help create coping strategies while in abusive relationships and aid emotional recovery post-separation; confidence-building sessions; emotional support at court hearings

$N$ in treatment group $=33 / 90=37 \%$

$N$ in control group $=17 / 88=19 \%$

3. Police Neighbourhood Team visit

On arriving at the address, the neighbourhood police officers would have checked on the welfare of the victim.

Then offered support to the victim as appropriate by BWA or the perpetrator for one-to-one counselling.

$N$ in treatment group $=54 / 90=60 \%$

$N$ in control group $=0 / 88=0 \%$

4. Joint Police and practitioner visit

The Enhanced IOM Practitioner visits to the home address, jointly with the Police Neighbourhood Team, would similarly be for support and welfare checks and offers of support to both parties as per the treatments being offered in the trial.

$N$ in treatment group $=30 / 90=33 \%$

$N$ in control group $=0 / 88=0 \%$

5. Enhanced IOM Practitioner visit

The practitioner would check on the welfare of the victim and perpetrator. Then, as appropriate, the victim would have been offered support by BWA. The offender was offered one-to-one counselling sessions with the Bracknell Forest Council Enhanced Integrated Offender Manager.

$N$ in treatment group $=24 / 90=27 \%$

$N$ in control group $=7 / 88=8 \%$

6. Perpetrator referral to counselling work/Plain Talking

The perpetrator will have engaged with the Enhanced Integrated Offender (IOM) practitioner, taking part in the Plain Talking programme, a one-to-one domestic abuse intervention oriented to individuals who are at the early stages of contemplation regarding their behaviour within a relationship.

$N$ in treatment group $=16 / 90=18 \%$

$N$ in control group $=6 / 88=7 \%$

7. Referral to DAPS one-to-one perpetrator counselling service

Referral of the offender to the Domestic Abuse Perpetrator Service (DAPS), a one-to-one perpetrator counselling service which utilizes a treatment programme of motivational interviewing techniques to address perpetrator ambivalence and to develop a motivation to change. A therapeutic alliance is formed between 
Table 2 (continued)

Service

the counsellor and the perpetrator which improves their capability to become responsible for the abusive and violent behaviour (Campbell et al. 2010). Goals relating to behaviour change are set and the counsellor then works to guide the perpetrator to achieve those goals.

$N$ in treatment group $=11 / 90=12 \%$

$N$ in control group $=10 / 88=11 \%$

The number of treatment contacts is 538 for the treatment group and 200 for the control group. The mean number per case is respectively 5.98 and 2.27. Again, there was the issue of contamination, though there is still a significant difference between the volumes of contact with the treatment group as compared to the control group.

The mean $N$ of treatment contacts is $163 \%$ higher than for control contacts.

The neighbourhood police staff visit has the largest difference of contacts between treatment and control group dyads (60 to 0 ), followed by the joint visit with the practitioner (33 to 1$)$. The DAPS referral has the smallest difference (1.09 to 0$)$. The biggest difference is in the neighbourhood policing team (NPT) contact. Only 36 out of the 178 cases did not receive the NPT treatment as randomly assigned (54 receiving it in the treatment group and zero receiving it in control group). That means that the overall treatment integrity for treatment as assigned on that basis was $80 \%$. A less positive view is that the average ratio of difference between treatment and control, 15.03 to 1, was not very high. If it is assumed that all the elements were equally important, then the experiment was a weak test of the theory that is a poor answer to the research question. Yet if the experiment is viewed with an emphasis on policing, even when police deliver their visits $2 / 3$ of the time, this might be enough to cause an improvement in outcomes. Especially when the control group remained uncontaminated by the NPT visits.

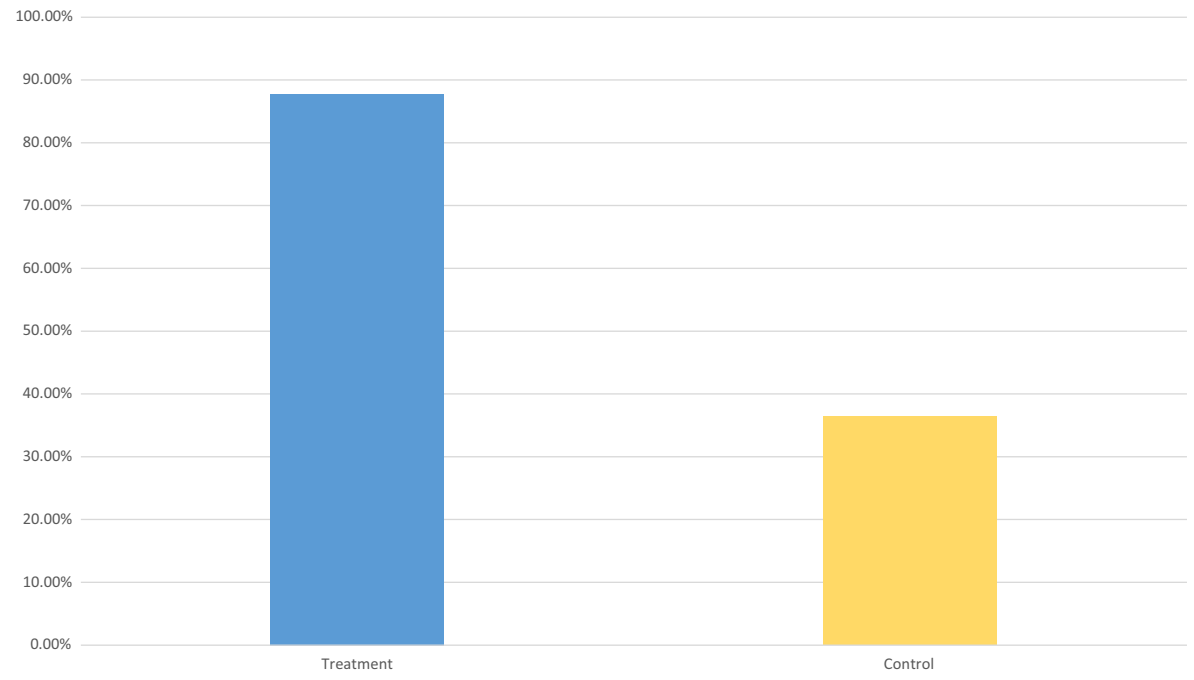

Fig. 2 Percentage of treatment and control dyads referred to any element of treatment 


\section{Outcomes}

Describing the Cases at Time of Random Assignment Table 3 provides a summary of the demographic statistics related to the cases. There is a very high level of consistency between the dyads randomized to the treatment and control groups. The eligibility criteria have also been met for these cases, whereby all the perpetrators were to be male and the victims to be female. The table shows that the victims' age across both the treatment and control groups is very close at only 0.5 year difference. Also, the average age of the perpetrators is very similar at 38.6 years for the treatment group and 38 years for the control group. Most of the victims and offenders in the dyads are of white British background. This is demographically representative of the Bracknell Forest area. Most importantly, the data shows that the random assignment process succeeded in creating two nearly identical groups in terms of the characteristics examined.

With respect to the comparability of the Crime Harm Index values, the experiment must deal with the problem of several cases that were extreme outliers. Because extremely serious offending is very rare in this sample, the sample is not large enough to ensure a balance between the treatment groups. This means that inclusion of outliers might create an unreliable conclusion, whereas removing them will allow a more homogeneous sample to produce a more reliable and externally valid conclusion - at some cost to internal validity.

The average CHI score per dyad for 2 years prior to random assignment, after the outliers have been removed, was 11.33 days for the treatment group and 7.47 days for the control group. All three outliers were removed from the control group (two were outliers in the pre-random assignment period, one post-randomisation). Therefore, the control count was 85 (for pairing purposes) and the treatment was 90. The 2 prerandomisation outliers were offences of rape with a high $\mathrm{CHI}$ value of 1825 each. Even when the outliers are removed, there is a chance difference that leaves the treatment group at baseline having suffered a higher level of harm. Thus, the analyses of CHI outcomes must emphasize differences of before-after differences between treatment and control groups, so that the analysis controls for the baseline bias against the treatment group.

Table 3 Summary of demographic statistics

\begin{tabular}{|c|c|c|c|c|}
\hline & \multicolumn{2}{|c|}{ Treatment $(N=90)$} & \multicolumn{2}{|c|}{ Control $(N=88)$} \\
\hline Victim female $(N=89)$ & \multicolumn{2}{|l|}{$100 \%$} & \multicolumn{2}{|c|}{$100 \%$} \\
\hline Perpetrator male $(N=89)$ & \multicolumn{2}{|l|}{$100 \%$} & \multicolumn{2}{|l|}{$100 \%$} \\
\hline Victim (average age) & \multicolumn{2}{|l|}{37.5} & \multicolumn{2}{|l|}{37} \\
\hline \multirow[t]{2}{*}{ Perpetrator (average age) } & \multicolumn{2}{|l|}{38.6} & \multicolumn{2}{|l|}{38} \\
\hline & Victim & Offender & Victim & Offender \\
\hline \multicolumn{5}{|l|}{ Ethnicity (\%) } \\
\hline - White & 93 & 92 & 90 & 85 \\
\hline - Black & 2 & 7 & 3 & 8 \\
\hline - Asian & 7 & 7 & 5 & 1 \\
\hline
\end{tabular}


The pre-randomisation mean CHI per treatment dyad is 11.33 and postrandomisation 2.31 , an $80 \%$ decrease in harm. The fact that the post-randomisation outliers are included does not impact on the CHI value for the treatment group since both outliers are in the control group. The pre-randomisation mean $\mathrm{CHI}$ per control dyad is 48.74 and the post-randomisation figure is 52.67 , an $8 \%$ increase in harm. The one crime outlier in the pre-period and the two crimes which are outliers in the postperiod have an impact on the control group only.

This is further illustrated in the 24 months before and after random assignment line graphs below, where Fig. 3 shows a difference of difference $P$ value of 0.824 for the treatment and control groups with the outliers included and Fig. 4 a difference of difference $P$ value of 0.033 without the outliers. The non-significant difference of differences implies only a chance difference in the effectiveness of the randomly assigned treatment as delivered in creating a changing trajectory of harm between the two groups.

Figures 5 and 6 as follows show relative percentage change of mean crime $\mathrm{CHI}$, with Fig. 5 including the outliers and Fig. 6 excluding the outliers. Both Figs. 5 and 6 begin at the starting point of $100 \%$ of the baseline period total $\mathrm{CHI}$ value, and show the percentage change in $\mathrm{CHI}$ from that baseline over the two years after random assignment.

With outliers included there is an $80.18 \%$ reduction in harm in the treatment group and an $8.58 \%$ increase in the control group.

In Fig. 5 where outliers in the control group are not taken out, the mean difference between the control (post) and control (pre) is an increase of $4.1534 \mathrm{CHI}$ days in prison whereas the mean difference between the treatment (post) and treatment (pre) is -8.8528 fewer $\mathrm{CHI}$ days in prison. The $\mathrm{T}$ test conducted is an independent $\mathrm{T}$ test with equal variance not assumed. The $P$ value is 0.824 . T was calculated: $t(148.641)=2.176$, $P=0.824$, so that the difference with the outliers included is not significant.

In Fig. 6 where the outliers in the control group are excluded, the mean CHI difference between the control (post) and the control (pre) is -4.5118 , and for the treatment group, it is -8.8528 . Since outliers are taken out in this case, it can be

Fig. 3 Mean crime CHI 24 months before and after random assignment (with outliers included) 


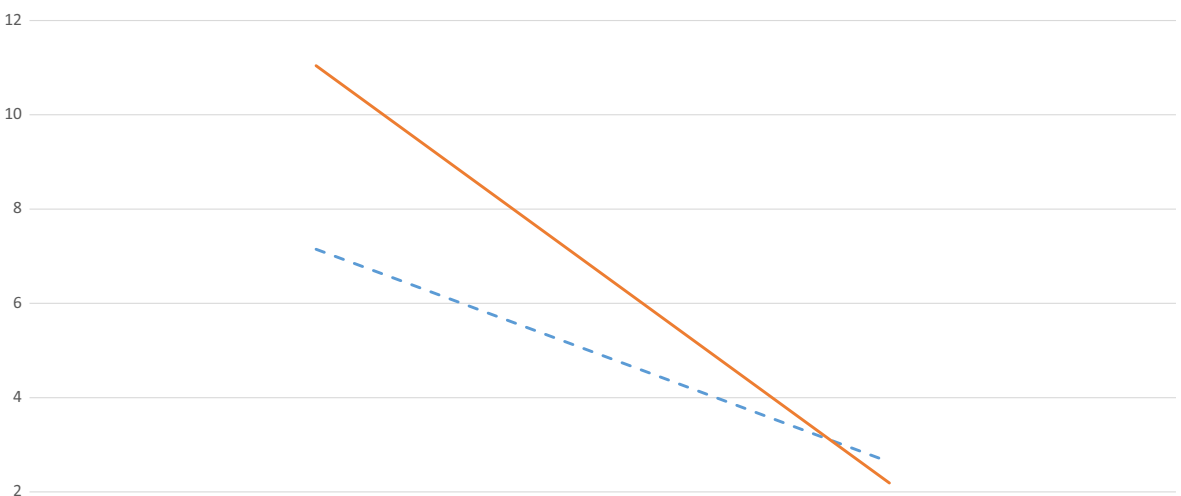

Fig. 4 Mean crime CHI 24 months before and after random assignment (without outliers)

assumed that the two data sets have equal variance. The $P$ value is 0.033 . T was calculated, $t(173)=2.147, P=0.033$, for a statistically significant result.

Prior to removing the outliers, the standard deviation was very high compared to the treatment group. For the control group, $N=88, \mathrm{M}=4.153, \mathrm{SD}=545.451$. For the treatment group, $N=90, \mathrm{M}=-8.852, \mathrm{SD}=16.026$. After the outliers were removed, the standard deviation for the control group becomes even lower than for the treatment group, $N=85, \mathrm{M}=-4.511, \mathrm{SD}=9.790$. For the treatment group, $N=90, \mathrm{M}=-8.852$, $\mathrm{SD}=16.026$. The reduction in variance increases the statistical power of the test, and its capacity to detect a true difference as not due to chance.

Mean Crime CHI Percentage Change

24 Months Before and After Random Assignment

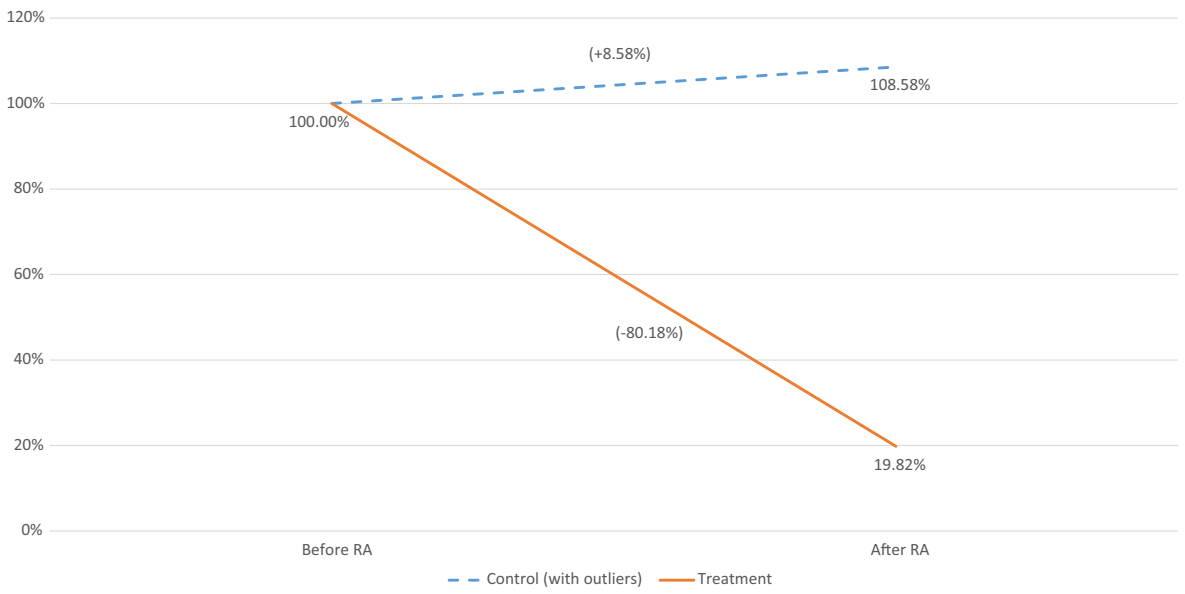

Fig. 5 Mean crime CHI percentage change 24 months before and after random assignment (with outliers included) 


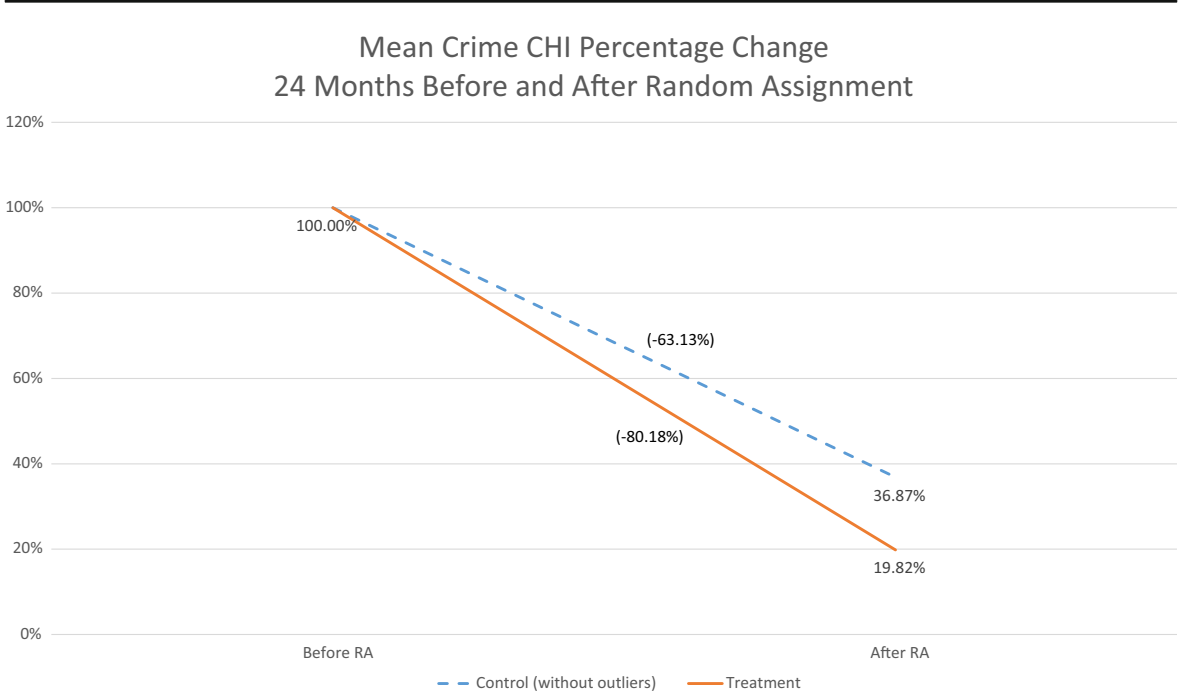

Fig. 6 Mean crime CHI 24 months before and after random assignment (without outliers). By excluding the outliers, Figure 6 shows the same $80.18 \%$ reduction of harm in the treatment group $(-80.18 \%)$ and a $63.13 \%$ decrease $(-63.13 \%)$ in the control group. The treatment group is not impacted by the removal of outliers; since it does not contain any of them, they are all positioned in the control group.

Summary of Outcomes The results clearly show the similarity at baseline of the dyads randomly assigned to the treatment group when compared to the control group in every respect except the $\mathrm{CHI}$ values. Even with outliers removed, the treatment group had a somewhat higher $\mathrm{CHI}$ value than controls. It is all the more impressive, then, that the $\mathrm{CHI}$ value for treatment cases dropped below the control cases during the 24-month post-random assignment period.

In reference to the CHI outcomes for the difference of difference test between the two before-after trends of the treatment groups, the $\mathrm{T}$ test where the outliers are included provides a $P$ value of 0.824 , which is not statistically significant. Whereas when the outliers were removed, the $P$ value is 0.033 , which is statistically significant. Since the removal of the outliers creates a more reliable test, the findings show that the treatment group did better by that test.

\section{Conclusions}

The RCT of the DASC project demonstrated the ability and potential of criminal justice and other partner agencies to work together to reduce harm. This alignment of shared priorities of partner agencies to try to reduce the harm was the first randomized control trial of its kind in the UK. In collaboration with Cambridge University Institute of Criminology, the partnership was sustained through the whole trial; the partners did agree to do the RCT and the trial was completed with relatively high treatment integrity. All of these suggest that a multi-agency trial can be effected.

What the trial did not do was to show that this approach can reduce frequency or repeat IPV incidents. While all cases had a two-incident minimum over 1 year to enter the RCT, 
there was a post-randomisation disparity of 85 non-crime domestic incidents reported by the control group as compared to 112 for the treatment group (Goosey 2017). This study therefore reports one of the few clear differences between success in reducing harm but not frequency of repeat demand for police services (see also Sherman and Harris 2015). No matter how much demand police face, it seems that few would prefer a world in which police choose not to use a programme that can reduce harm just because it would increase demand.

This observation requires an emphasis on the fact that substantial portions of the control group also received some treatment. The likely effect of this contamination with some of the control group receiving the treatments, however, may have been to under-estimate the benefits of the programme. Had the control group received no treatment at all, the crime and harm suffered in that group might have been even greater, creating an even greater relative difference with the treatment group and increasing the cost-effectiveness of the DASC programme.

The elements of treatment in this experiment can be divided into two groupspolice-led and partner-agency led. The police-led treatments were offered to more of the dyads than the partner-led treatments. This means that the results may be more attributable to the police-led treatments. To test this and further expand the evidence base, another experiment would need to be run only the police-led treatments against the partner-led treatments.

The most important finding from this experiment is the success of a multi-agency partnership agreeing to launch a randomized trial of a programme for dealing with repeated domestic abuse. The Bracknell Forest experiment may well be a first in this regard. The agreement to set aside opinions about what works in order to provide clear test results is an essential first step for evidence-based policing and its promise to help reduce the harm caused by domestic violence.

The statements and conclusions in this study are those of the authors and do not necessarily represent the views of the Thames Valley Police, the College of Policing, or the partner agencies participating in the study. The first author thankfully acknowledges the support of many people who have contributed to this research, especially former Chief Constable Sara Thornton of Thames Valley Police, who provided him with the opportunity to study at the University of Cambridge where this research was conducted as a master's thesis in the Cambridge Police Executive Programme. He also acknowledges the partner agencies working in Bracknell Forest who are named in the study for their continued support over the whole period of the trial, without which the trial would not have been completed. The financial support of the College of Policing was also essential to the completion of the study. Finally, we acknowledge the support of both Professor Heather Strang and Dr. Barak Ariel of the Cambridge University Institute of Criminology, who helped to design the trial and provided the random assignment sequences needed to carry it out.

Open Access This article is distributed under the terms of the Creative Commons Attribution 4.0 International License (http://creativecommons.org/licenses/by/4.0/), which permits unrestricted use, distribution, and reproduction in any medium, provided you give appropriate credit to the original author(s) and the source, provide a link to the Creative Commons license, and indicate if changes were made. 


\section{References}

Barnham, L., Barnes, G. C., \& Sherman, L W. (2017). Targeting escalation of intimate partner violence: evidence from 52,000 offenders. Cambridge Journal of Evidence-Based Policing, 1-27.

Bland, M., \& Ariel, B. (2015). Targeting escalation in reported domestic abuse evidence from 36,000 callouts. International Criminal Justice Review, 25(1), 3053.

Campbell, M., Neil, J. A., Jaffe, P. G., \& Kelly, T. (2010). Engaging abusive men in seeking community intervention: a critical research \& practice priority. Journal of Family Violence, 25(4), 413-422.

Dunford, F. W. (1990). Random assignment: practical considerations from field experiments. Evaluation and Program Planning, 13(2), 125-132.

Farmer, E., \& Callan, S. (2012). Beyond violence. Breaking cycles of domestic abuse. London: Centre for Social Justice.

Goosey, J (2017). The effects of an integrated case management programme on domestic abuse in Bracknell: A randomised controlled trial. MSt thesis, Institute of Criminology: University of Cambridge.

Office for National Statistics (ONS), (2013). Focus on violent crime and sexual offences 2012/13 - chapter 4: intimate personal violence and partner abuse. Retrieved from: http://www.ons.gov.uk/ons/dcp171776 352362.pdf

Robbins, R., McLaughlin, H., Banks, C., Bellamy, C., \& Thackray, D. (2014). Domestic violence and multiagency risk assessment conferences (MARACs): a scoping review. The Journal of Adult Protection, 16(6), 389-398.

Schulz, K. F., Altman, D. G., \& Moher, D. (2010). CONSORT 2010 statement: updated guidelines for reporting parallel group randomized trials. Annals of Internal Medicine, 152(11), 726-732.

Sherman, L. W. (2010). An introduction to experimental criminology. In Handbook of quantitative criminology (pp. 399-436). New York: Springer.

Sherman, L. W., \& Berk, R. A. (1984). The specific deterrent effects of arrest for domestic assault. American Sociological Review, 261-272.

Sherman, L. W., \& Harris, H. M. (2015). Increased death rates of domestic violence victims from arresting vs. warning suspects in the Milwaukee Domestic Violence Experiment (MilDVE). Journal of Experimental Criminology, 11(1), 1-20.

Sherman, L. W., Smith, D. A., Schmidt, J. D., \& Rogan, D. P. (1992). Crime, punishment, and stake in conformity: legal and informal control of domestic violence. American Sociological Review, 680-690.

Sherman, L., Neyroud, P. W. and Neyroud, E. (2016). The Cambridge Crime Harm Index: measuring total harm from crime based on sentencing guidelines. Policing, 10(3), 171-183. 